\title{
Sensitivity of TOMS aerosol index to boundary layer height: Implications for detection of mineral aerosol sources
}

\author{
Natalie M. Mahowald ${ }^{1}$ and Jean-Louis Dufresne ${ }^{2}$ \\ Institute for Computational Earth Systems Science, University of California, Santa Barbara, California, USA \\ Received 17 October 2003; revised 12 November 2003; accepted 6 January 2004; published 4 February 2004.
}

[1] The TOMS aerosol index (AI) is proposed as a powerful tool in determining the sources of mineral aerosols. The sensitivity of the AI to the height of the aerosol layer has been noted previously, but the implications of this sensitivity for deducing sources has not been explicitly considered. Here, we present a methodology and sensitivity test to show the importance of spatial and temporal variations of the planetary boundary layer height to deducing sources using the AI. These results suggest that while dry topographic low sources may be large sources of desert dust, conclusions eliminating other sources may be premature, especially when these sources occur on the edges of deserts, where boundary layer heights are lower, and human influences potentially more important. The compounding problem of differentiating downwind transport and local sources suggests it may not currently be possible to use the AI to conclusively determine mineral aerosol source regions. INDEX TERMS: 0305 Atmospheric Composition and Structure: Aerosols and particles (0345, 4801); 0315 Atmospheric Composition and Structure: Biosphere/ atmosphere interactions; 1610 Global Change: Atmosphere (0315, 0325); 1615 Global Change: Biogeochemical processes (4805); 0365 Atmospheric Composition and Structure: Troposphere - composition and chemistry. Citation: Mahowald, N. M., and J.-L. Dufresne (2004), Sensitivity of TOMS aerosol index to boundary layer height: Implications for detection of mineral aerosol sources, Geophys. Res. Lett., 31, L03103, doi:10.1029/2003GL018865.

\section{Introduction}

[2] Identifying the sources of mineral aerosol has been a difficult process, due to the complex natural and anthropogenic processes which are involved in entraining soil particles into the atmosphere [e.g., Okin and Gillette, 2001]. In situ studies [e.g., Marticorena and Bergametti, 1995; Gillette, 1998] of the soil particle size distribution and chemical and mineralogical characteristics can provide data about easily erodible soils, but global maps of these characteristics are not available at the resolution required. The Herman et al. [1997], Prospero et al. [2002], Ginoux et al. [2001] and Goudie and Middleton [2001] studies marked a large step forward, by showing from the TOMS aerosol index (TOMS AI) and other data that dry lake bed areas (or topographic lows) appear to be the strongest sources.

\footnotetext{
${ }^{1}$ Also at Bren School of Environmental Science and Management, UCSB; Now at National Center for Atmospheric Research, Boulder, USA.

${ }^{2}$ Also at Laboratoire de M'eteorologie Dynamique, Paris, France.

[3] In Prospero et al. [2002] they identify the strongest sources of mineral aerosols as those areas with persistent, high TOMS aerosol index (using a threshold of 0.7 , except over North Africa, the Middle East and Central Asia where the threshold is 1.0); while in the Goudie and Middleton [2001] study they use mean TOMS AI. However, the TOMS aerosol index (TOMS AI) is well known to have a strong sensitivity to the height of the aerosol layer [Torres et al., 1998; Prospero et al., 2002]. Indeed the Prospero et al. [2002] study suggests that there is a strong correlation of the TOMS AI to planetary boundary layer height. However, no one has explored explicitly what the sensitivity to boundary layer height implies for detecting sources using the TOMS AI. In this paper we conduct a sensitivity study including the effects of planetary boundary layer height (PBLH) on the TOMS AI, and look for areas of persistent 'significant' aerosols, similar to Prospero et al. [2002] for the region of North Africa. Our sensitivity study consists of calculating a seasonally- and spatially-varying 'threshold' that includes the effect of the PBLH, but assumes a constant column of dust and thus a constant dust source minus sink.

\section{TOMS Aerosol Index Sensitivity to PBLH}

[4] The presence of uv-absorbing aerosol amount is detected from TOMS measurements using a spectral contrast method in a UV region where the ozone absorption is very small [Herman et al., 1997; Torres et al., 1998]. In cloud free conditions, this measurement (called the TOMS

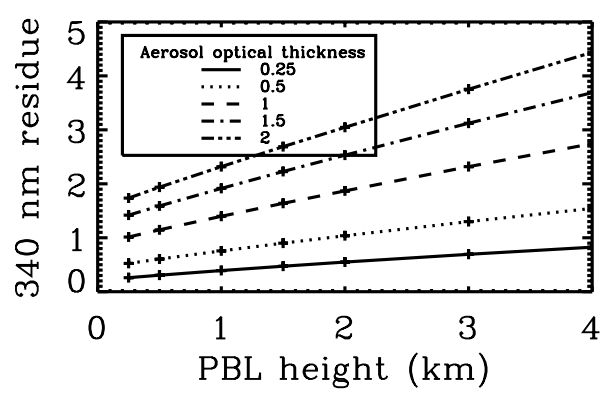

Figure 1. Dependence of the TOMS AI at $340 \mathrm{~nm}$, defined as the $340 \mathrm{~nm}$ residue, as a function of the PBLH, for various aerosol optical thicknesses at $380 \mathrm{~nm}$. The aerosol mixing ratio decreases linearly with height and reaches zero at the top of the PBL. The aerosol size distribution follows a lognormal distribution $\left(\mathrm{r}_{0}=0.50 \mu \mathrm{m}\right.$, $\sigma=2.2)$ and the refractive index comes from Sinyuk et al. [2003]. Other conditions are solar zenith angle $40^{\circ}$, nadir view for the satellite, surface reflectivity 0.05 , summer midlatitude atmospheric profile. 


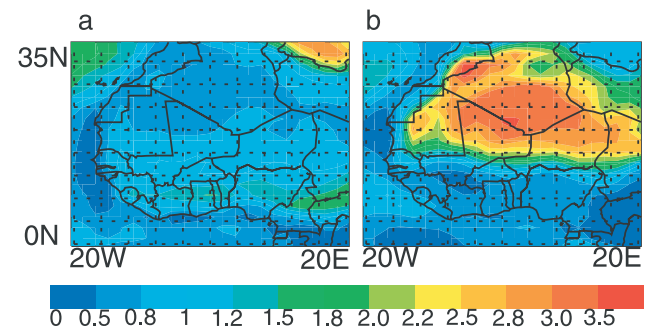

Figure 2. Monthly averaged local noon boundary layer heights for January (a) and July (b), 1981, from the MATCH model, in $\mathrm{km}$.

aerosol index or $\mathrm{AI}$ ) depends on the amount, size distribution, optical properties and height of absorbing aerosols, the presence of clouds and the viewing geometry [Herman et al., 1997; Torres et al., 1998]. Here we would like to calculate the TOMS AI as a function of optical depth and PBLH. We consider desert dust particles close to the sources and thus, to allow intercomparison, we use the particle size distribution of the "d3" aerosol type from Torres et al. [1998] and the optical properties updated in Sinyuk et al. [2003]. All other conditions (atmosphere, zenith angle, surface reflectivity) are the same as in Torres et al. [1998] and we have verified that our results were almost insensitive to these conditions. The atmospheric radiative transfer is computed with the SBDART code [Ricchiazzi et al., 1998] that incorporates the LOWTRAN7 band models [Pierluissi and Peng, 1985] and the DISORT discrete ordinate method [Stamnes et al., 1988]. Our computations reproduce the published results of Torres et al. [1998] if the optical properties from that paper are used instead of the updated Sinyuk et al. [2003] values.

[5] We assume a simple vertical profile with dust in the boundary layer, with a linearly decreasing mixing ratio of mineral aerosol with height and the concentration of zero above the planetary boundary layer height (PBLH). This aerosol distribution is the solution to a Fick's Law type vertical diffusion, assuming there is a constant surface flux with strong mixing and removal from the column at the top of the boundary layer (presumably transport downwind). For this aerosol vertical profile, our calculation using the SBDART code for the dependence of the TOMS AI with the PBLH is displayed in Figure 1 for various aerosol optical thicknesses. Sensitivity tests suggest that parameters which have uncertainties (e.g., vertical aerosol profile, index of refraction or size distribution) do not change the almost

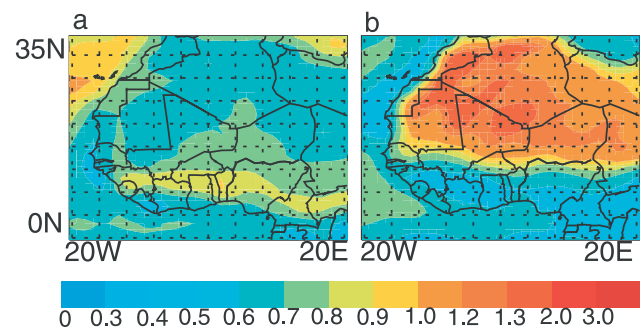

Figure 3. TOMS AI thresholds (refered to as PBLHthresholds in text), assuming an optical thickness of 0.5 in Figure 1, and the boundary layer heights in Figure 2 for January (a) and July (b), 1981.

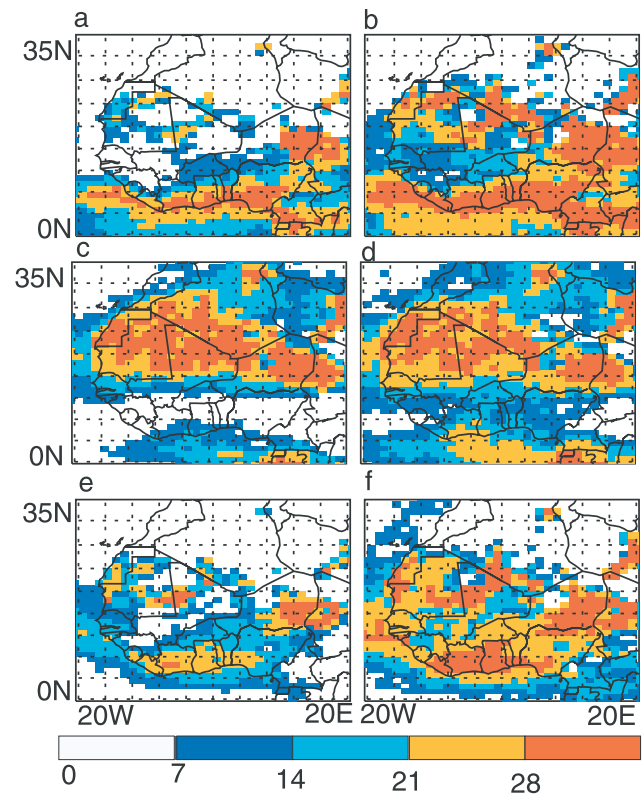

Figure 4. Number of days of 'significant' dust events for using a constant threshold of 1.0 for January (a), July (c), and November (e) and using time and spatially varying thresholds from Figure 3 for January (b), July (d), and November (f) for 1981 (similar to Figure 2 from Prospero et al. [2002]).

linear relationship between PBLH and TOMS AI, although they do change the slope of the relationship. If instead, optical properties from Torres et al. [1998] were used, the AI for a zero PBLH shown in Figure 1 would be much lower, suggesting much smaller TOMS AI for dust close to the surface than using the optical properties as updated in Sinyuk et al. [2003] (not shown). TOMS AI retrievals from satellite also depend on cloud reflectivity - here we exclude days when the reflectivity is higher than 0.2 , to exclude cloudy pixels.

\section{Implications for Sources Areas}

[6] For ease of use and global coverage, we use PBLH derived from the MATCH model using the National Center for Environmental Prediction/National Center for Atmospheric Research (NCEP) reanalysis [Mahowald et al., 1997; Rasch et al., 1997; Kalnay et al., 1996]. We archived daily averaged values, however, and the diurnal cycle in boundary layer heights is very strong, especially in desert areas. The TOMS AI is calculated from satellite observations close to noon local time. From a 10-day simulation of the diurnal cycle in the model, we calculate that the best estimate of the $11 \mathrm{am}-1 \mathrm{pm}$ boundary layer height from the daily average boundary layer height is (noon average $=$ (daily average * 24-nighttime average * 12)/12), where the nighttime average is $200 \mathrm{~m}$ (for more information, see the auxiliary material ${ }^{1}$ ). The monthly averaged noon boundary layer heights for January and July are shown in Figure 2 for 1981. The noon averaged boundary layer heights are very high (greater than $3 \mathrm{~km}$ ) in some desert regions in the dry

\footnotetext{
${ }^{1}$ Auxiliary material is available at $\mathrm{ftp} / / / \mathrm{ftp}$.agu.org/apend/g1/ 2003GL018865.
} 
season, and much lower elsewhere (500-1000 m), even in adjoining regions, as well as in the wet season or winter. The seasonality and height of the boundary layers over arid regions appear to be consistent with our understanding of boundary layer heights and available observations [e.g., Garratt, 1992; Wai et al., 1997].

[7] To highlight regions covered by a 'significant' amount of mineral aerosol, Prospero et al. [2002] use a threshold TOMS AI of 0.7 in most of the world, and use 1.0 over North Africa, the Middle East and Central Asia (which we will call a fixed-threshold) and calculate the number of days during each month that this value is exceeded. In order to highlight similar areas, we define a new spatially- and temporallyvarying threshold (referred to here as the PBLH-threshold) from Figure 2 as the TOMS AI corresponding to a boundary layer aerosol with an optical depth of 0.5. Clearly, the PBLH-threshold is very different depending on the location and month of the year, as seen in Figure 3 for January and July of 1981, where it varies by a factor 4 seasonally and spatially. Notice that the regions of high PBLH in this analysis correspond to a large extent with the regions identified by Goudie and Middleton [2001] as dominant sources. This suggests the possibility that these regions are not necessarily the strongest sources, but rather regions with high PBLH with desert dust aerosols. For the Bodele basin, for example, if the source was upwind to the northeast, boundary layer heights go from 1.8 to $3.0 \mathrm{~km}$ in a short distance. Thus dust from these dust sources may have a substantially higher TOMS AI when they are advected downwind over the Bodele basin where they will be vertically mixed. Note that the highest boundary layer heights are associated with regions where the sensible heat flux is greatest, and latent heat flux is small due to lack of vegetation and water sources. In addition in desert regions there are few clouds, thereby increasing the surface absorption of solar radiation (however the surface albedo of deserts versus vegetated regions will tend to counter these effects). Thus, boundary layer heights in very arid regions in the central part of the desert may be systematically higher (and result in higher TOMS AI for the same source strength) than in slightly wetter regions on the edges of deserts, where humans disturbance is more likely [e.g., http://www.ornl.gov/gist/ projects/LandScan/landscan_doc.htm; Dobson et al., 2000].

[8] The use of time varying thresholds for the TOMS AI is supported by observations available outside the sources regions. During winter, when the "Saharan dust layer" over the North Atlantic is lower, the satellite retrieved TOMS AI is lower for a given optical depth measured at aeronet ground stations than during summer [Hsu et al., 1999].

[9] For comparison, we show the number of days that the satellite retrieved TOMS AI are above the fixed-threshold from Prospero et al. [2002] in Figures 4a, 4c, and 4e, for the months of January, July, and November, 1981, respectively (similar to Prospero et al. [2002] Figure 2). Next we calculate the frequency that the satellite retrieved TOMS $\mathrm{AI}$ is above the PBLH-thresholds (shown in Figures $4 \mathrm{~b}, 4 \mathrm{~d}$, and $4 \mathrm{f}$ for January, July, and November, respectively). Note that if we looked at the percentage of retrieval days with high dust (instead of absolute number of days) we would obtain similar results. An important effect of using the PBLH-threshold, compared with using the fixed-threshold is to change the very strong seasonal cycle seen in previous studies [e.g., Prospero et al., 2002], to be more consistent with visibility studies of the region [Mbourou et al., 1997], which show much less dust during the summer. We will not address the biomass burning sources, such as in Africa between about $10^{\circ} \mathrm{N}$ and $15^{\circ} \mathrm{S}$, nor TOMS AI over ocean regions. Notice that in July, 1981, the frequency of high dust seen in North Africa between $15^{\circ} \mathrm{N}$ and $30^{\circ} \mathrm{N}$ west of $0^{\circ} \mathrm{E}$ is higher than east of $0^{\circ} \mathrm{E}$, implying that the dust is not advected (e.g., from Bodele basin), but rather appear to be from a local source in this analysis. It is not possible to determine whether this large area of high dust frequency is more consistent with the 'disturbed' sources suggested by Tegen and Fung [1995] or Mahowald et al. [2002] or a topographic low, as suggested by Prospero et al. [2002] since this region includes many seasonal lakes as well as humans and domestic animals.

[10] In Figure 4, we show the frequency of 'significant' aerosol events in January (Figures $4 \mathrm{a}$ and $4 \mathrm{~b}$ ) and November (Figures $4 \mathrm{e}$ and $4 \mathrm{f}$ ). These months have the lowest amount of persistent areas, and thus the methodology of Prospero et al. [2003] would use these months to suggest the location of the sources during the whole year. This sensitivity study suggests that in January or November, the removal of the effect of boundary layer height on the TOMS AI increases the area with days with 'significant' aerosol amounts substantially in the western part of the Sahel, on the southern edge of the Sahara, and changes them very little in the central desert regions. Again, these regions appear to be local sources, not downwind advection from the Bodele basin. The methodology of choosing the month in which the index is generally lowest, and suggesting that the areas with many days above the 'significant' threshold are the most important sources during other times of the year may not be robust. In some areas, there may be low wind speeds as well as low planetary boundary layer heights during the low TOMS AI months, and that may be why there is less mineral aerosols detected by the TOMS AI. Other months may have very different sources [e.g., Marticorena and Bergametti, 1996].

\section{Summary and Conclusions}

[11] Prospero et al. [2002] identify regions with persistent 'significant' aerosol amount as the most likely source regions for mineral aerosols using a fixed threshold; while Goudie and Middleton [2001] use mean TOMS AI. These studies have suggested that most of the mineral aerosol comes from dry lake beds in the current climate and not from the large expanses of desert such as the Sahara-an important observation that has assisted many global modelers in improving their mineral aerosol simulations [e.g., Ginoux et al., 2001]. In addition, they argue that the topographic low source areas are not substantially impacted by anthropogenic activities.

[12] But as noted in previous studies [e.g., Torres et al., 1998; Prospero et al., 2002], the TOMS AI is sensitive to the height of the aerosol layer. We have conducted a simple sensitivity study here, where we use a monthly and spatially varying threshold based on boundary layer height to identify the source regions for one year; 1981. The inclusion of the boundary layer height based thresholds suggests that previous studies may have underestimated the importance of sources on the edges of deserts or other areas where the boundary layer depths are systematically lower than in 
topographic lows in the central desert regions. For example, in Figure 4e, the high TOMS AI across North Africa at 15$20 \mathrm{~N}$ west of $0 \mathrm{E}$ appears to not be downwind advection from the Bodele basin, but rather a local source of the potentially the same strength as the Bodele basin. This region is a region with roads and is likely to have human impacts [e.g., http:// www.ornl.gov/gist/projects/LandScan/landscan_doc.htm; Dobson et al., 2000]. Thus, the TOMS AI is consistent with anthropogenic sources of dust if the sensitivity of the TOMS AI to boundary layer height is included.

[13] Identification of the sources of mineral aerosols from satellite retrieved aerosol absorption is inherently a hard problem due to the difficulty of determining whether observed mineral aerosols have been transported or have a local source. Other studies have shown that modeled source magnitudes are not well correlated with modeled aerosol optical depths due to downwind transport [Mahowald et al., 2003]. Because the TOMS AI is less sensitive to aerosols at a low altitude, this index may not be able to conclusively determine sources. Instead, identification of sources from surface process studies such as Chomette et al. [1999] using satellite retrieved surface properties, or in situ studies such as Marticorena and Bergametti [1995], Gillette [1988] offer invaluable data about the erodibility of soils. These types of surface oriented studies are required to eliminate or confirm source regions on a global scale. Nevertheless, the TOMS AI represents an excellent long term series of measurements enabling us to better understand the sources, transport, distribution and deposition of mineral aerosols.

[14] Acknowledgments. The TOMS AI data used in this paper was kindly made available by the NASA/GSFC TOMS Ozone Processing Team (OPT). We would like to acknowledge the support of NASA through the NIP and IDS programs, and NSF through the Biocomplexity project. This paper benefited from conversations with Omar Torres, Paul Ginoux, Greg Okin, Johann Fedema, Masaru Yoshioka, Chao Luo and the comments of two anonymous reviewers. We appreciate the substantial computer assistance provided by John del Corral.

\section{References}

Chomette, O., M. Legrand, and B. Marticorena (1999), Determination of the wind speed threshold for the emission of desert dust using satellite remote sensing in the thermal infrared, J. Geophys. Res., 104(D24), $31,207-31,245$.

Dobson, J. E., E. A. Bright, P. R. Coleman, R. C. Durfee, and B. A. Worley (2000), A Global Poulation Database for Estimating Population at Risk, Photogrammetric Engineering \& Remote Sensing, 66(7).

Garratt, J. R. (1992), The atmospheric boundary layer, Cambridge Atmospheric and Space Science Series, Cambridge, England, 316 pp.

Gillette, D. A. (1988), Threshold friction velocities for dust production for agricultural soils, J. Geophys. Res., 93(D10), 12,645-12,662.

Ginoux, P., M. Chin, I. Tegen, J. Prospero, B. Holben, O. Dubovik, and S. J. Lin (2001), Sources and distributions of dust aerosols simulated with the GOCART model, J. Geophys. Res., 106(D17), 20,255-20,273.

Goudie, A., and N. Middleton (2001), Saharn dust storms: Nature and consequences, Earth-Science Reviews, 56, 179-204.

Herman, J. R., P. K. Bhartia, O. Torres, C. Hsu, C. Seftor, and E. Celarier (1997), Global distribution of UV-absorbing aerosols from Nimbus 7/ TOMS data, J. Geophys. Res., 102(D14), 16,911-16,922.
Hsu, N. C., J. R. Herman, O. Torres, B. N. Holben, D. Tanre, T. F. Eck, A. Smirnov, B. Chatenet, and F. Lavenu (1999), Comparisons of the TOMS aerosol index with Sun-photometer aerosol optical thickness: Results and applications, J. Geophys. Res., 104(D6), 6269-6279.

Kalnay, E., M. Kanamitsu, R. Kistler, W. Collins, D. Deaven, L. Gandin, M. Iredell, S. Saha, G. White, J. Woollen, Y. Zhu, M. Chelliah, W. Ebisuzaki, W. Higgins, J. Janowiak, K. C. Mo, C. Ropelewski, J. Wang, A. Leetmaa, R. Reynolds, R. Jenne, and D. Joseph (1996), The NCEP/NCAR 40-Year Reanalysis Project, Bulletin American Meteorological Society, 77(3), 437-471.

Mahowald, N. M., P. J. Rasch, B. E. Eaton, S. Whittleston, and R. G. Prinn (1997), Transport of 222Radon to the remote troposphere using MATCH and assimilated winds from ECMWF and NCEP/NCAR, J. Geophys. Res., 102(D23), 28,139-28,151.

Mahowald, N., C. Zender, C. Luo, D. Savoie, O. Torres, and J. del Corral (2002), Understanding the 30-year Barbados desert dust record, J. Geophys. Res, 107(D21), 4561, doi:10.1029/2002JD002097.

Marticorena, B., and G. Bergametti (1995), Modeling the atmospheric dust cycle: 1 . Design of a soil-derived dust emission scheme, J. Geophys. Res., 100(D8), 16,415-16,430.

Marticorena, B., and G. Bergametti (1996), Two-year simulations of seasonal and interannual changes of the Sahran dust emission, Geophys. Res. Lett., 23(15), 1921-1924.

Mbourou, G. N. T., J. J. Bertrand, and S. E. Nicholson (1997), The Diurnal and Seasonal Cycles of Wind-Borne Dust over Africa North of the Equator, J. Applied Meteorology, 36(July 1997), 868-882.

Okin, G. S., and D. A. Gillette (2001), Distribution of vegetation in winddominated landscapes: implications for wind erosion modeling and landscape processes, J. Geophys. Res., 106(D9), 9673-9683.

Pierluissi, J. H., and G.-S. Peng (1985), New molecular transmission band models for LOWTRAN, Opt. Eng., 24(3), 541-547.

Prospero, J., P. Ginoux, O. Torres, and S. E. Nicholson (2002), Environmental Characterization of Global sources of atmospheric soil dust derived from the NIMBUS-7 TOMS absorbing aerosol product, Rev. Geophys., 40(1), 1002, doi:10.1029/20000GR000095.

Rasch, P. J., N. M. Mahowald, and B. E. Eaton (1997), Representations of transport, convection and the hydrologic cycle in chemical transport models: Implications for the modeling of short-lived and soluble species, J Geophys. Res, 102(D23), 18,127-28,138.

Ricchiazzi, P., S. Yang, C. Gautier, and D. Sowle (1998), SBDART: A research and teaching software tool for plane-parallel radiative transfer in the Earth's atmosphere, Bull. of Am. Meteorol. Soc., 79, $2101-2114$.

Stamnes, K., S.-C. Tsay, W. Wiscombe, and K. Jayaweera (1988), Numerically stable algorithm for discrete-ordinate-method radiative transfer in multiple scattering and emitting layered media, Appl. Opt., 27, 25022509.

Sinyuk, A., O. Torres, and O. Dubovik (2003), Combined use of satellite and surface observations to infer the imaginary part of the refractive index of Saharan dust, Geophys. Res. Lett., 30(2), 1081, doi:10.1029/ 2002GL016189.

Tegen, I., and I. Fung (1995), Contribution to the atmospheric mineral aerosol load from land surface modification, J. Geophys. Res., 100(D9), 18,707-18,726.

Torres, O., P. K. Bhartia, J. R. Herman, Z. Ahmad, and J. Gleason (1998), Derivation of aerosol properties from satellite measurements of backscattered ultraviolet radiation: Theoretical basis, J. Geophys. Res., 103(D14), $17,099-17,110$

Wai, M.-M. K., E. A. Smith, P. Beemoulin, A. D. Culf, A. J. Dolman, and T. Lebel (1997), Variability in boundary layer structure during HAPEXSahel wet-dry season transition, J. Hydrology, 188-189, 965-997.

J.-L. Dufresne and N. M. Mahowald, Institute for Computational Earth Systems Science, University of California, Santa Barbara, CA 93106, USA. (mahowald@ucar.edu) 